\title{
Study on the Importance of Implementing Green Buildings to Environmental Protection
}

\author{
Jianmei Xu \\ Tianjin University, Tianjin, China, 300072
}

Keywords: Importance, Green Buildings, Environmental Protection

\begin{abstract}
To promote healthy, energy saving, sustainable development of green building ideas and practice came into being in this situation, and quickly swept the country, for the construction industry to provide long-term feasible areas of development. This paper discusses the significance of green building's protection to the ecological environment from the real meaning of green building and the necessity of implementing green building and puts forward some reasonable suggestions.
\end{abstract}

\section{Introduction}

The development of human society to today, whether it is economic, cultural or technology have made significant achievements, to achieve a qualitative leap, ecology and development has become a major proposition of this century. In the process of building a comprehensive urbanization in our country, the construction industry has always been playing an important role and played a certain role in promoting it. At the same time, the construction industry caused by energy consumption, environmental pollution, ecological damage and other issues more and more attention from all walks of life, building energy has become the focus of common concern, people began to re-examine and evaluate the previous works of construction and the value system. We know that human and natural ecological environment is closely related to the sustainable development of ecological environment is the conditions and prerequisites for socio-economic development to sacrifice the ecological environment at the expense of the construction and development model, will inevitably react to the construction of human society. Therefore, we should stand on the priority of protecting the environment level, improve the construction engineering mode, the quality of the project, take the road of environmental protection and energy conservation ecology, and the green building concept and its practice and research is precisely for this goal to achieve a clear "green" direction.

In the 21st century, such a large background of the environment, the rapid development of the economy, the rapid progress of the times, we pursue material interests, at the expense of the environment, waste of resources, leading to floods, debris flow, desertification, water pollution, air pollution and other natural ecological problems frequent, the survival of mankind has a great threat, which, a large part of the construction is brought by the construction. In order to avoid the problem, the pioneers of the construction industry tried to improve the status quo by building green buildings, to protect the ecological environment, in order to coordinate the harmonious development of human ecological environment.

\section{The Value System of Green Building}

The Concept and Characteristics of Green Building. As a new concept, green building is also a dynamic, developmental concept. However, in the context of promoting green environmental background to understand the concept of green building, as the name suggests, is a green building features or buildings. But it is not limited to a green living area, a demonstration building and its connotation is very large. In terms of its concept, it is a lot of professional integrated cooperation, is the construction of the whole life cycle of the performance of the environment, the consumption of resources and the impact of the balance and the environment. As a prerequisite for the construction of the building system must be able to save resources, resources and energy can be recycled and use, 
to reduce the characteristics of climate pollution, so as to maximize the health of people to ensure that the index and labor efficiency.

Analysis on the Composition of Green Building Value System. "Green" is the basic measure of the green building system, specific to the social and technical aspects can be divided into section, energy, water, materials, space environmental quality, life cycle management and comprehensive performance of six aspects. Therefore, the premise of green building design must change the traditional design concepts and methods to reduce the variety of resources, energy consumption and waste disposal for the operation of the line, from the building space environment, life cycle investment and the impact on the natural environment and other aspects of comprehensive consideration, and then make a reasonable design layout. Extension of technical processing, the requirements of its building materials must be environmentally friendly and energy-efficient, the outer layer can be used as energy collection, conversion interface, and to prevent energy loss, while the structure also have to adjust the climate to ensure that the indoor climate stability.

The green building system based on the principle of benign circulation of ecosystem has rich the meaning of "green life", which includes the concept of energy, design and technology. It has the mechanism of health and regeneration, so that the building and people And ecosystems to form an intelligent and efficient environment that does not pollute the environment and survive, so that the building can get rid of the excessive reliance and consumption of existing resources to a certain extent to ensure that the use of energy self- the value of the green building system.

\section{The Green Building Design}

Green building value system to green as a measure of its design concept must take into account the energy saving, water saving, land, materials, to ensure the quality of space environment, the entire life cycle of operation and management, comprehensive performance of six aspects, Sewage treatment, energy use, the surrounding environment, insulation, lighting, ventilation and other consideration, reasonable layout, to avoid waste of resources, pollution, lack of comfort and other issues brought about by a series of trouble. Architects need to have a detailed and detailed grasp of the environment, it is necessary to take into account the green concept in the use and implementation of the environment, but also deal with every detail, to create a comprehensive and sustainable development of the living environment. In this regard, the architects need to understand the relevant aspects of the building planning and design stage to fully consider every aspect, in addition, the architect should be combined with local customs, natural resource conditions, economic conditions, climate conditions, according to local conditions, choose the most suitable design, material half a cup when the surgery, to avoid wasting local resources, destruction of the environment to the local residents when the tongue inconvenience.

\section{The Importance of Implementation of Green Building on Environmental Protection}

First, the development of green building is necessary to solve the energy shortage. Energy is the life of building development, the construction industry is the main system of energy consumption and many high energy consumption, high input, low efficiency of the building makes the energy problem increasingly serious. Some people will say that Chinese vast land, rich natural energy, but dead water afraid of scoop, and then rich resources without reasonable planning and utilization, do not take energy conservation, regeneration, sustainable development of the road, the human will eventually face energy depletion, ecological environment contaminated mirror. In fact, Chinese per capita possession of natural resources relative to the world average is at a very low level. In the face of the severe test of the times, the value of the green building system has given its historical mission, which is the necessary way to solve this important problem under the current social conditions. Second, it is an important measure to solve climate pollution. Nowadays, climate anomalies are a major challenge facing the world, and climate issues are on the agenda. Objective reality makes people realize that the development of the construction industry not only caused energy shortage, but also become an important culprit in the manufacture of natural climate pollution. One of the 
main sources of greenhouse gas emissions is a large number of buildings, which have a very large impact on the climate and environment. And basically all the buildings need to use artificial lighting and mechanical air conditioning, which is the building on the climate and environmental pollution a major reason. According to statistics, $50 \%$ of global energy consumption is caused by the construction and use of the building. Green building with low energy consumption, low greenhouse gas emissions is characterized by energy-saving emission reduction theme to address climate change has played an important role in solving a major climate problem is a pioneering work. Therefore, in order to protect the ecological environment, to achieve sustainable development of energy, to maintain human ecological balance and harmony, we must vigorously promote the development of green buildings. This is in the promotion of low-carbon environmental protection, follow the principles of natural ecological construction under the premise of the development of human society is an inevitable choice, it will be related to human long-term future.

Vigorously promote the green building is the need to protect the ecological environment Construction, environment, human three are inseparable, the role involved in each other, the construction industry is the main system of energy consumption, in order to create a healthy, safe and sustainable development of life, must Development of green building. Construction of irrational construction can bring environmental pollution, waste of resources and other issues, such as unreasonable use of resources, a large number of greenhouse gas emissions, arbitrary discharge of sewage, green building with low energy consumption, low greenhouse gas emissions is characterized by the solution to global warming and other climate change issues played an important role. in fact. Green building does not mean high cost and it does not mean that advanced technology, the use of low energy consumption of environmentally friendly materials to reduce maintenance costs, in the long run but cost savings. At the same time, for some old buildings, the green building concept of its use of its transformation, but also can make it more long-term, for urban construction is also a major contribution.

\section{Opinions and Suggestions on the Development of Green Building in China}

Green building in our country has been more and more attention and attention, have also been deployed around the construction of green building tasks and has been put into practice part, but also made from the initial results, but in the construction process still exposed a series of problems to be strengthened and resolved. And developed countries compared to China is still far behind them, we adhere to the premise of the green concept, but also should strengthen the efficiency of the reality of the process.

For the current problems facing our country, we need to do the following: l) Strengthen government intervention. The development of green buildings is not only the architect's own task, they use the construction expertise to design and design, but the government as a strong backing need to give them financial, technical, diplomatic and other aspects of support, to provide them with foreign advanced experts exchange and cooperation And learning opportunities, so as to contribute to the progress of Chinese green building. 2) Continue to develop new technologies, new materials. With the new environmentally friendly materials, the protection of new technologies, the construction of green building will play a greater role and the effect will be more obvious. 3) Raise people's attention to green building. The protection of the ecological environment is closely related to everyone, everyone's support for green buildings and encouragement for the whole society is beneficial enhances the people's consensus without delay.

Intuitive current green building in China to develop the status quo, sum up the problem, combined with the reality, our current primary task should be adjusted from the following aspects: (1) Enhance government intervention. Retrospect the development of foreign green buildings, the role of policy to promote a huge. Therefore, our government departments should also increase the emphasis on green building, the establishment of effective incentive policies to improve the relevant industries, enterprises and individuals to promote the green building development. As the leader of the development of the government, the implementation of many encouraging and guiding policies, 
green building development will achieve a multiplier effect. (2) green building development laws and regulations to be improved. The development of anything depends on the guidance, control and protection of the relevant laws and regulations, and the green building is no exception. China is the only country in the form of a country to promote green building countries, in the improvement of relevant laws and regulations on a more social impact, should be based on our situation, give the power of the people to speed up the improvement of green building uniform standards and local standards system to ensure that the standard Can cover different climate zones and different types of buildings. (3) need more theoretical, more applicable to the technical support. Green building is a step-by-step grasp one of the most important part is the theoretical research and practice statistics. We should vigorously promote the green concept to make people deeply rooted in the foreign advanced theory and technology strategy on the basis of local conditions, choose and create suitable for the local green building technology, take the Chinese characteristics of the green building development.

\section{Conclusion}

The building comes from nature to catch the natural, in the face of today's energy and the environment two major problems, green building to promote and develop into a dominant trend, to protect the protection of the ecological environment is of vital importance. But to increase the promotion of green building development has yet to be brainstorming for all mankind for the development of green building system to create a more favorable and broad space.

\section{References}

[1] Gao Jiaxu, Qi Yaan. On the green building of the contemporary application and development prospects [J]. Green building materials. 2017 (02)

[2] Li Qiang. On the construction of green ideas of the infiltration of ideas to explore[J]. Shanxi Architecture. 2016 (30)

[3] Zhang Minghui, Zhang Xiaoxia, Zhu Yongying, Feng Yixing. Green building construction management under LEED evaluation system[J]. Green Technology. 2016 (02)

[4] Li Yifan. On the future development trend of the building[J]. Shanxi Architecture. 2015 (20)

[5] Zou Xiaofeng. Analysis of the development of green ecological architecture[J]. Value Engineering 2015 (18)

[6] Ye Haowen, Zou Jun, Sun Hui, Yang Wei. key technology of green construction in chow tai fook financial center in guangzhou [J]. Construction Technology. 2015 (10) 